\section{ACUTE EDEMA OF THE LUNGS.}

\author{
BY
}

\begin{abstract}
G. E. BEAUMONT, M.A., M.D. Oxf., F.R.C.P., D.P.H. LoND.,

IHYSICIAN TO THE BROMPTON HOSPITAL; ASSISTANT PHYSICLAN TO THE MIDDIESEX HOSPITAL.
\end{abstract}

Acute cedema of the lungs is a rare disease, first described by Laennec in 1819 as a fatal complication of measles in children. It is, however, of importance as it constitutes one of the emergencies of medical practice.

The clinical picture of the disease is striking, yet owing to the comparative infrequency with which it is encountered a correct diagnosis is not always made at first. In a typical case the patient who has previously been in good health is suddenly seized with dyspnœa, and within a short time becomes semi-unconscious or completely so. A sense of terror, pallor of the skin, and sweating are often noted in the early stages. There may be some preliminary warning just before the attack begins, such as pain in the head or neck, or a sense of faintness. The patient may then become unconscious, and the only noticeable features are the dyspnœa, slight cyanosis, and pallor. The cardiac action is usually regular, and the pulse of good volume and tension, but in some cases it is frequent and feeble. In a typical case, after a variable period of a few minutes to half an hour or so, a certain amount of frothy fluid runs up into the mouth from the lungs. This fluid is often stained pink, and continues to well up from the lungs into the mouth and nose as long as the attack persists.

Examination of the lungs in the early stages of the attack will give the clue to the correct diagnosis, for they will be found to be full of bubbling râles which extend from the base to the apex. These are caused by the air passing in and out of the alveoli and finer bronchi which are flooded by the exudation. The duration of an attack is very variable, death may occur within 10 to 15 minutes, or the patient may succumb after lying unconscious for several hours: in other cases recovery takes place after a variable period, and in some instances repeated attacks may occur.

Very little is known about the rtiology of cedema of the lungs, and there are probably several contributory causes. Thus it may be associated with aortic disease, arterio-sclerosis, myocarditis, or chronic nephritis, and it may be met with in pregnancy, in diabetes, or in certain nervous conditions. In other instances it is thought to be a manifestation of angioneurotic œdema, or to result from such operations as paracentesis of the thorax or abdomen. Acute œdema of the lungs has also been recorded as a complication of acute infective diseases, such as typhoid fever, measles, influenza, pneumonia, and rheumatic fever, or it may occur as a terminal phase in pulmonary tuberculosis.

\section{A Group of Theories.}

The various theories propounded to account for the occurrence of acute oedema of the lung are mainly speculative and to a certain degree lacking in support. They may be grouped under certain headings applicable to the various clinical manifestations of the condition mentioned above.

The Cardiac Theory.-There is thought to be a disproportion between the working power of the left and right ventricle, so that the left expels a little less blood in a given time than does the right. The result is that stagnation occurs in the left auricle and the pressure in the pulmonary vessels is raised. This theory is based on the experimental work of Prof. W. H. Welch, who produced œdema of the lungs in rabbits by squeezing the left ventricle between the finger and thumb and partially paralysing it.

The Periaortitis Theory.-The inflammatory process is thought to spread from the aorta to the cardiopulmonary plexus, with resulting increase of tension in the pulmonary vessels, and failure of the right ventricle.

The Toxic Theory.-This is advanced to explain those cases which are associated with chronic nephritis, pregnancy, and infectious diseases in which there is no cardiovascular lesion.

The Angioneurotic Theory.-The rapid onset of an attack in a patient who is apparently in good? health, and in some cases the simultaneous appearance of odema of the face, supports the theory that the pulmonary œdema may be in certain instances a manifestation of angioneurotic œdema.

\section{Three Cases Described.}

Three cases of acute œdema of the lungs have occurred in my practice during the last few months, and in view of the rarity of the condition a brief description may not be out of place. All were of the female sex.

CASE 1 was a single woman aged 42 , who had previously enjoyed good health. For a few months before the onset of her fatal illness it had, however, been noticed that she was somewhat irritable. Apart from this she was apparently in perfect health and, while having tea, she complained of a severe headache and in a few minutes became unconscious. Her breathing was embarrassed and was soon accompanied by audible bubbling sounds. After about an hour fluid began to well up into the mouth and trickled slowly from the nose and mouth. The fluid was stained pink. Examination of the chest showed that the lungs were full of bubbling râles. Her pulse was regular, 120 per minute, but there was no indication of a cardiac lesion, and the sounds at the apex were quite strong. The blood pressure was $120 \mathrm{~mm}$. systolic. No specimen of urine was available for examination. The patient died three and a half hours from the onset without recovering consciousness, the lungs becoming completely waterlogged. Injections of morphine and atropine were of no avail.

CASE 2 was that of a woman aged 37 , who, on the day of her fatal illness, had just returned from a holiday, and 
was, apparently, in good health. When sitting down to dinner in the evening she complained of a tight feeling across the forehead and neck; she immediately vomited and lost consciousness within a fow minutes. She did not recover consciousness and died four hours from the onset. In this case also the frothy fluid did not appear in the mouth until one hour after the beginning of the attack, the lungs became gradually waterlogged, the lower lung showing more numerous râles than the upper when the patient was lying on her side. The blood pressure was slightly raised, being $140 \mathrm{~mm}$. systolic, and the heart was definitely hypertrophied. In this case also a specimen of urine was not available, as the patient had passed it involuntarily at the onset of the attack. When her relatives arrived it was ascertained that she had had scarlet fever three years ago and had been subsequently put on a diet from which meat was excluded owing to high blood pressure. The fluid continued to well up into the mouth and nose as long as respiratory movements were made. Morphine and atropine injections did not benefit her.

CAse 3 was a woman aged 62 , who was suddenly taken ill during the night after a journey to London. She became very dyspnœic, cold and cyanosed, with a feeble and rapid pulse, and the lungs were full of bubbling râles. In this case consciousness was not lost and the pulmonary œdema was not so severe, as frothy fluid did not well up into the mouth. Injection of morphine gr. $\frac{1}{6}$ and atropine gr. 1/100 was followed by a wonderful result, the dyspnœea and bubbling in the lungs being immediately relieved. The next morning the lungs were clear, except for some œdema of the left lower lobe. Definite signs of cardiovascular degeneration were present, the heart being enlarged, the arteries thickened, the systolic blood pressure $170 \mathrm{~mm}$., and the urine contained much albumin. The patient gave a history of an attack of acute nephritis following a chill 15 years previously, and had suffered from a septic throat five years before this. No difficulty in breathing had been noted until the last nine months, during which the patient had had several minor attacks of nocturnal dyspnœa.

The subsequent convalescence was notable for the rapidity with which the albuminuria vanished. A small pleural effusion developed on the left side, which was absorbed without aspiration. The patient proved to be an example of the recurrent or paroxysmal type of acute pulmonary cdema, which has been described by several authors. Thus attacks have been known to extend over a period of 10 years, and as many as 72 seizures during a space of two years have been recorded. It has also been noted that this recurrent variety is nearly always associated with cardiovascular disease or with nephritis.

Almost a year later this patient had a second attack, the lungs becoming flooded with fluid and the pulse-rate rising to 132. The attack again occurred at about 2 A.M., and was aborted by an injection of morphine gr. $\frac{1}{4}$ and atropine gr. 1/100. The urine was once more loaded with albumin, whereas only a week previously it had been examined and found free from protein. Vomiting occurred several times during the following morning, and a small pleural effusion again appeared on the left side with some residual œdema at the right base and a little dry pleurisy.

A week later the patient had a third attack which was less severe than the previous ones, and again responded well to morphine and atropine injections.

\section{Diagnosis and Treatment.}

At the onset of the attack the question of a cerebral vascular lesion or coma from some other cause naturally arises. As soon, however, as the codema of the lungs appears and the fluid wells up into the mouth there is little doubt as to the correct diagnosis. In less severe cases in which there is not such a copious exudation the presence of bubbling râles in the lungs may suggest the diagnosis of acute suffocative catarrh as opposed to acute suffocative pulmonary œdema. The former is, however, an infective process, known also as acute purulent bronchitis, and associated with purulent expectoration and pyrexia.

There is no doubt that the most efficacious treatment consists in the immediate injection of morphine in doses up to gr. $\frac{1}{3}$. This is strongly in favour of the disease having a cardiac origin. Atropine gr. 1/100 is usually given in conjunction with the morphine, although its use is probably not essential. In cases which are likely to recover the injection usually affords very rapid relief. Other methods which are recommended are venesection, inhalation of amyl nitrite, and dry cupping. It is very doubtful, however, if any form of treatment will succeed if an injection of morphine and atropine fail.

\section{ABDOMINAL TUBERCLLOSIS IN CHILDREN.*}

\author{
BY \\ C. E. SUNDELL, M.D. LoND.,
}

CONSULTING PHYSICIAN, EVELINA HOSPITAL FOR CHILDREN, ETC.

INFECTION of the abdominal cavity and its contents by tubercle is apt to assume forms of striking severity in the child in contrast to their comparative rarity in the adult. In the lattero abdominal tuberculosis in a severe form is usually a late event in the course of tuberculosis elsewhere in the child it is far more often the major or only disability. Not only is this the case but it is also true that in the child who manifests signs of tuberculosis elsewhere the oldest lesion is to be found in the majority of cases in the abdomen. Experience in the post-mortem room shows clearly that when tuberculous bronchial glands or tuberculous invasion of the lung are found in a child some involvement of the abdominal contents is almost invariably present. To find this it may be necessary to examine closely any. enlarged glands in the mesentery and to explore the thoracic duct, in such glands or in the lumen of this duct are often to be found evidences of tubercle which remain unrevealed to a hurried and casual inspection.

\section{The Route of Infection.}

Whatever views may be held as to the route of tuberculous infection as met with in the adult, there can be no question that in the child the alimentary tract is the common portal of entry. Apart altogether from the danger of tubercle-infected milk (a danger which is yearly becoming smaller owing to quickening of the health-conscience of the community), the floor-loving and toy-sucking propensities of the young child expose it to the risk of swallowing tubercle-infected dust at all hours of the day.

* A Lecture delivered at the North-East London Post-Graduate College on July 23rd, 1926. 